\title{
NUTRITION IN RHEUMATOID ARTHRITIS: A CROSS SECTIONAL STUDY IN 71 FEMALES
}

Nelzi Ferreira de Queiroz Junior ${ }^{1, \star}$, Kamilla de Bessa Jorge ${ }^{1}$, João Gabriel Cavazzani Doubek ${ }^{1}$, Barbara Stadler Kahlow ${ }^{1}$, Thelma Larocca Skare ${ }^{1}$

1.Hospital Universitário Evangélico Mackenzie, Curitiba (PR), Brazil.

*Corresponding author: nelzi@hotmail.com

\section{BACKGROUND}

In rheumatoid arthritis (RA) patient's survival may be decreased due to lung impairment, infections, and cardiovascular diseases associated with accelerated atherosclerosis. Nutrition is also impacted in these individuals and may further aggravate the disease's morbidity and mortality. Cachexia in RA is different from classic cachexia due to inadequate dietary consumption and associated with weight loss. In RA, the muscle loss is compensated by an increase in body fat, so the body mass index (BMI) remains unaltered or even higher than previously and it is called obese cachexia. The aim of this study was to study the nutritional profile in RA female patients and its association with disease activity, function, clinical and treatment parameters.

\section{METHODS}

Data on disease activity (SDAl and CDAI), function (HAQ), epidemiological, clinical and treatment were obtained from 71 females with RA. Mini-nutritional assessment (MNA) and electrical bioimpedance to study body composition were also obtained.

\section{RESULTS}

By the MNA, 24/71 (33.8\%) patients were undernourished or at malnutrition risk. An impaired nutritional state associated with $\operatorname{SDAI}(p=0.02), \operatorname{CDAl}(p=0.02)$ and HAQ $(p=0.002)$. No associations of MNA with medications, age and disease duration were found ( $p=n s$ ). By bioimpedance, $98.5 \%$ of patients had the percentage of body fat above normal and $95.7 \%$ had lean mass under normal. Bioimpedance results did not associate with disease activity or HAQ but the percentage of body fat was lower in those using abatacept $(p=0.01)$.

\section{CONCLUSION}

Almost $1 / 3$ of RA patients from this sample were undernourished or at risk for it, mainly those with high disease activity and low function. Body fat was above normal in almost the whole sample and associate negatively with abatacept use.

\section{KEYWORDS}

Rheumatoid arthritis, Nutrition, Inflammation. 